\title{
Evolutionary and Developmental Contributions for Understanding the Organization of the Basal Ganglia
}

\author{
Loreta Medina Antonio Abellán Alba Vicario Ester Desfilis \\ Laboratory of Brain Development and Evolution, Department of Experimental Medicine, Faculty of Medicine, \\ University of Lleida, Institute of Biomedical Research of Lleida (IRBLleida), Lleida, Spain
}

\section{Key Words}

Developmental regulatory genes · Enkephalin · Forebrain evolution · Globus pallidus · Islet 1 · Nkx2.1 · Pallidostriatal projections · Pallidum · Striatum

\begin{abstract}
Herein we take advantage of the evolutionary developmental biology approach in order to improve our understanding of both the functional organization and the evolution of the basal ganglia, with a particular focus on the globus pallidus. Therefore, we review data on the expression of developmental regulatory genes (that play key roles in patterning, regional specification and/or morphogenesis), gene function and fate mapping available in different vertebrate species, which are useful to (a) understand the embryonic origin and basic features of each neuron subtype of the basal ganglia (including neurotransmitter/neuropeptide expression and connectivity patterns); (b) identify the same (homologous) subpopulations in different species and the degree of variation or conservation throughout phylogeny, and (c) identify possible mechanisms that may explain the evolution of the basal ganglia. These data show that the globus pallidus of rodents contains two major subpopulations of GABAergic projection neurons: (1) neurons containing parvalbumin and neurotensin-related hexapetide (LANT6), with descending projections to the subthalamus and substantia nigra, which originate from progenitors expressing Nkx2.1, primar-
\end{abstract}

ily located in the pallidal embryonic domain (medial ganglionic eminence), and (2) neurons containing preproenkephalin (and possibly calbindin), with ascending projections to the striatum, which appear to originate from progenitors expressing Islet 1 in the striatal embryonic domain (lateral ganglionic eminence). Based on data on Nkx2.1, Islet1, LANT6 and proenkephalin, it appears that both cell types are also present in the globus pallidus/dorsal pallidum of chicken, frog and lungfish. In chicken, the globus pallidus also contains neurons expressing substance $P(S P)$, perhaps originating in the striatal embryonic domain. In ray-finned and cartilaginous fishes, the pallidum contains at least the Nkx2.1 lineage cell population (likely representing the neurons containing LANT6). Based on the presence of neurons containing enkephalin or SP, it is possible that the pallidum of these animals also includes the Islet 1 lineage cell subpopulation, and both neuron subtypes were likely present in the pallidum of the first jawed vertebrates. In contrast, lampreys (jawless fishes) appear to lack the pallidal embryonic domain and the Nkx2.1 lineage cell population that mainly characterize the pallidum in jawed vertebrates. In the absence of data in other jawless fishes, the ancestral condition in vertebrates remains to be elucidated. Perhaps, a major event in telencephalic evolution was the novel expression of Nkx2.1 in the subpallium, which has been related to Hedgehog expression and changes in the regulatory region of $\mathrm{Nkx2.1}$.

(c) 2014 S. Karger AG, Basel

\begin{tabular}{ll}
\hline KARGER & ( 2014 S. Karger AG, Basel \\
& $0006-8977 / 14 / 0832-0112 \$ 39.50 / 0 \quad$ Karger \\
E-Mail karger@karger.com & This is an Open Access article licensed under the terms of the \\
www.karger.com/bbe & $\begin{array}{l}\text { Creative Commons Attribution-NonCommercial 3.0 Un- } \\
\text { ported license (CC BY-NC) (www.karger.com/OA-license), } \\
\text { applicable to the online version of the article only. Distribu- } \\
\text { tion permitted for non-commercial purposes only. }\end{array}$
\end{tabular}

Loreta Medina, $\mathrm{PhD}$

Faculty of Medicine, University of Lleida

Institute of Biomedical Research of Lleida (IRBLleida)

Avenida Alcalde Rovira Roure 80, ES-25198 Lleida (Spain)

E-Mail loreta.medina@mex.udl.cat 


\begin{tabular}{|c|c|c|c|}
\hline \multicolumn{4}{|c|}{ Abbreviations used in this paper } \\
\hline A9/A10 & catecholaminergic cell groups & $\mathrm{P}$ & pallium \\
\hline Bas & nucleus basalis (Meynert) & p1-p3 & prosomeres $1-3$ \\
\hline BST & bed nucleus of the stria terminalis & $\mathrm{Pa}$ & pallidal subdivision (MGE in mammals) \\
\hline CALR & calretinin & Pir & piriform cortex \\
\hline $\mathrm{cc}$ & corpus callosum & $\mathrm{PO}$ & preoptic subdivision \\
\hline E13.5 & embryonic day 13.5 & ppENK & preproenkephalin \\
\hline Emt & thalamic or prethalamic eminence & proj. neur. & projection neuron \\
\hline En & endopiriform nucleus & $\mathrm{Pt}$ & pretectum \\
\hline ENK & enkephalin & PTh/Pth & prethalamus (ventral thalamus) \\
\hline Ept & epithalamus & PV & parvalbumin \\
\hline GP & globus pallidus (dorsal pallidum) & $\mathrm{SNr}$ & substantia nigra pars reticulata \\
\hline LGE & lateral ganglionic eminence & st & stria terminalis \\
\hline $\mathrm{MB}$ & midbrain & St & striatal embryonic division (LGE in mammals) \\
\hline MGE & medial ganglionic eminence & STN & subthalamic nucleus \\
\hline MGEd & dorsal sudivision of MGE & svz & subventricular zone \\
\hline MGEcv & caudoventral subdivision of MGE & Th & thalamus (dorsal thalamus) \\
\hline $\mathrm{NCx}$ & neocortex & $\mathrm{vZ}$ & ventricular zone \\
\hline
\end{tabular}

\section{Introduction}

The basal ganglia are a group of nuclei located in the ventral or subpallial part of the telencephalon, which are key actors of functional neural networks involved in the control of motivation and somatomotor behavior [reviewed by Reiner et al., 1998; Medina, 2009; Moreno et al., 2009; Kuenzel et al., 2011; Medina and Abellán, 2012]. These nuclei are not only involved in the execution of tasks, they also play important roles in cognitive functions essential for adaptive behavior, such as planning, attention, learning and memory [reviewed by Reiner et al., 1998; Gerfen, 2004; Graybiel and Saka, 2004; Medina, 2009; Lanciego et al., 2012]. Basal ganglia dysfunction is associated with a variety of human diseases or disorders, including Parkinson's disease, obsessive-compulsive disorder or drug addiction, and understanding the basis of their clinical manifestations requires deep knowledge of the function of each single neuron subpopulation [Albin et al., 1989; Reiner et al., 1998].

In spite of the vast amount of research dedicated to the study of basal ganglia in different species, and the fact that there is a high degree of evolutionary conservation of these nuclei across tetrapods [Marín et al., 1998; Reiner et al., 1998; Moreno et al., 2009; Kuenzel et al., 2011], many aspects on their functional anatomical organization and evolution remain unanswered. This is due to the high complexity of these nuclei, each comprising many different subtypes of neurons with different chemical features (expression of neurotransmitters, neuropeptides and receptors, for example), connections and physiological properties [reviewed by Reiner et al., 1998; Medina, 2009; Lanciego et al., 2012].

Modern developmental studies using tools for analyzing gene expression, gene function and fate mapping help to understand the embryonic origin and basic features of each neuron subtype of the basal ganglia and other subpallial structures, such as the centromedial extended amygdala [Marín et al., 2000; García-López et al., 2008; Hirata et al., 2009; Carney et al., 2010; Nóbrega-Pereira et al., 2010; Bupesh et al., 2011a, b; Abellán et al., 2013]. In the centromedial amygdala, this information is key to unraveling its functional anatomical organization in mammals and to establish the basis for comparisons with other species [Moreno et al., 2009; Medina et al., 2011; Abellán et al., 2013]. We expect that such studies applied to the basal ganglia and done in different species in the light of evolutionary developmental biology [Wullimann and 
Mueller, 2004; Medina, 2009; Moreno et al., 2009] will be essential in order to be able to: (a) identify the same molecularly distinct progenitor zones that produce neurons for the basal ganglia nuclei in different species ${ }^{1}$; (b) know whether basal ganglia nuclei in different species, if present, are formed by identical or partially different sets of neuron subpopulations (identified by their embryonic origin and transcription factor expression during development), and (c) identify possible mechanisms that may explain the evolution of the basal ganglia (for example, changes in the expression of developmental regulatory genes, and in the enhancers, activators, repressors and/or cofactors that regulate the expression), taking into account that evolution of morphological diversity is the consequence of nonlethal changes that occurred during development and were preserved by natural selection [Carroll et al., 2001; Medina, 2007]. Therefore, herein, we take advantage of the evolutionary developmental biology (evodevo) approach in order to improve our understanding of both the functional organization and the evolution of the basal ganglia, focusing our attention on the analysis of the globus pallidus (dorsal pallidum). To that aim, we review data on the development of the basal ganglia in mammals and compare them to those obtained in other vertebrates.

\section{Striatum versus Pallidum: Were They Present in the First Vertebrates?}

Developmental, neurochemical and connectivity data show that the basal ganglia contain two major subdivisions in all jawed vertebrates studied: an input station called striatum and an output station called pallidum (see reviews by Marín et al. [1998]; Reiner et al. [1998]; Medina [2009] and González et al. [2014]), and recent data in lobe-finned fishes (e.g. lungfishes) [González and Northcutt, 2009], ray-finned fishes (e.g. the teleost zebrafish) [Wullimann and Mueller, 2004; Mueller et al., 2008; Mueller and Wullimann, 2009], and cartilaginous fishes (e.g. the lesser-spotted dogfish) [Rodríguez-Moldes, 2009; Quintana-Urzainqui et al., 2012]. Moreover, two major divisions are distinguished at least in tetrapods, the dorsal basal ganglia mainly related to somatomotor behavior, in-

\footnotetext{
1 Note that the same progenitor zones should not only be identified by their molecular profile but, most importantly, they should occupy an identical position within the topological framework of the neural tube [Nieuwenhuys, 1998; Puelles and Medina, 2002; Striedter, 2005; Medina, 2007; Nieuwenhuys, 2009].
}

cluding the dorsal striatum (the caudoputamen complex in mammals) and the dorsal pallidum (the globus pallidus in mammals), and the ventral basal ganglia mainly related to motivation, including a ventral striatum (nucleus accumbens and other cell groups) and a ventral pallidum [Marín et al., 1998; Reiner et al., 1998]. However, the situation is unclear in jawless fishes: while some developmental data point to the absence of a pallidal embryonic domain in the subpallium of lampreys (based on the lack of Nkx2.1 expression [Murakami et al., 2001; Osorio et al., 2005; see also van den Akker et al., 2008]), recent data on neurochemistry combined with connections and physiology have identified a globus pallidus in these jawless fishes [Stephenson-Jones et al., 2011, 2012]. In the following, we review new data on the development of the globus pallidus/dorsal pallidum in mice, sauropsids and other vertebrates that contribute to a better understanding of the neuronal components of this center and may help to reconcile the discrepancy in the views on its early evolution.

\section{The Globus Pallidus in Mammals: Multiple Neurons and Multiple Embryonic Origins}

In mammals, the striatum (including the caudoputamen complex) and the pallidum (including the rodent globus pallidus, comparable to the primate lateral globus pallidus) were classically considered to derive from distinct embryonic domains, named the lateral ganglionic eminence (LGE) and the medial ganglionic eminence (MGE), respectively [Holmgren, 1925], which was later demonstrated experimentally using tritiated-thymidine autoradiography [Fentress et al., 1981; Marchand and Lajoie, 1986]. This was recently corroborated based on the results of gene expression patterns and several fate map approaches, including fluorescent clonal labeling and genetic fate mapping using transgenic mice [Marín et al., 2000; Puelles et al., 2000; reviewed by Marín and Rubenstein, 2001; Yun et al., 2001; Stenman et al., 2003; Yun et al., 2003; Xu et al., 2008; Medina, 2009; Medina and Abellán, 2012]. In particular, during development LGE and MGE express distinct combinations of transcription factors in the ventricular (vz) and/or subventricular zone (svz), some of which are also expressed in postmitotic cells allowing identification of LGE and MGE derivatives in the mantle [Grigoriu et al., 1998; Marín et al., 2000; Puelles et al., 2000; Marín and Rubenstein, 2001; Yun et al., 2001; Stenman et al., 2003; Yun et al., 2003; Flames et al., 2007; García-López et al., 2008; Xu et al., 2008; Medina and Abellán, 2012]. LGE vZ and/or svz and their derivatives 


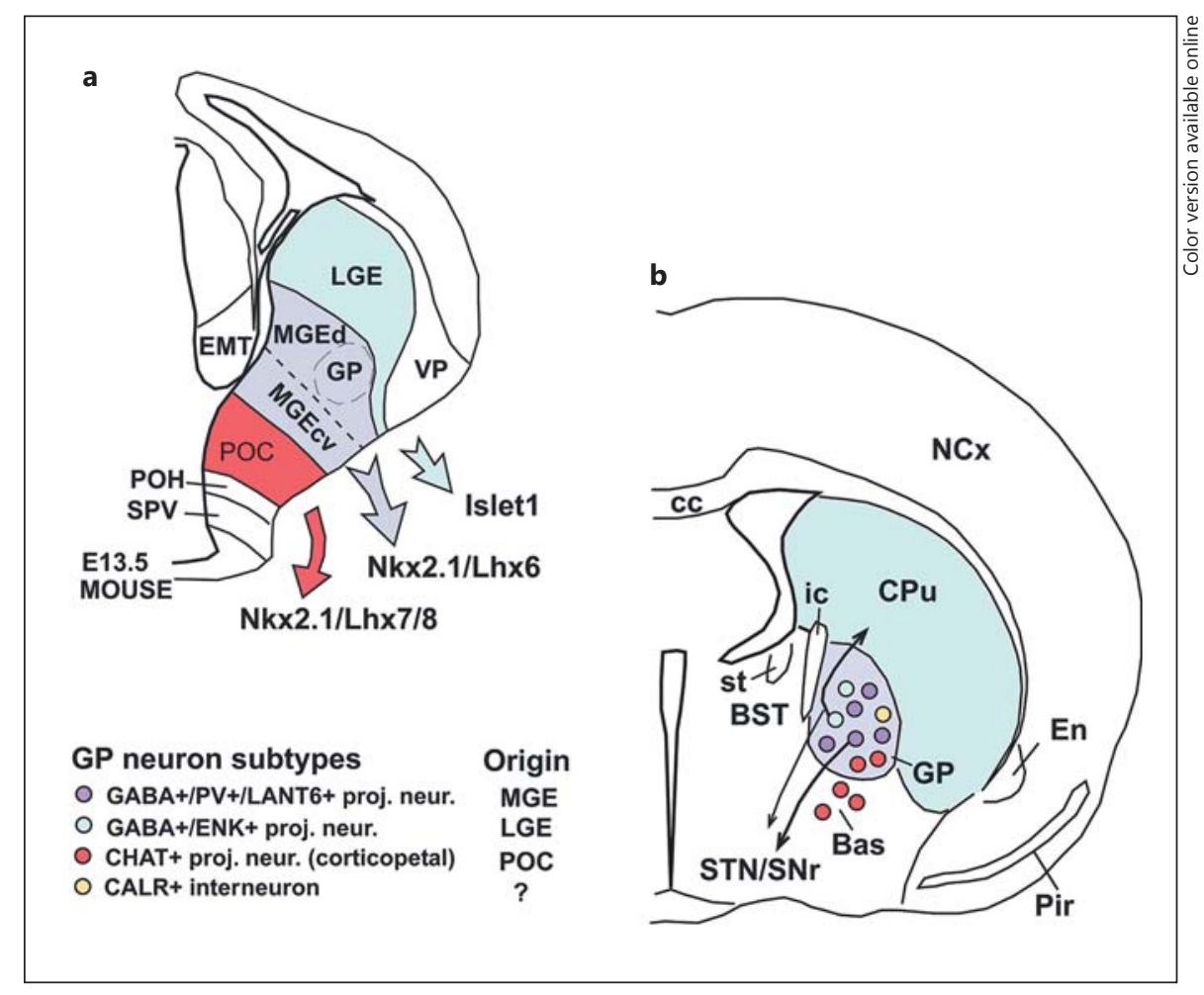

Fig. 1. Diagrams of frontal sections through the early embryonic (a) or postnatal (b) telencephalon of a mouse, representing the neuron subtypes found in the globus pallidus in rodents and indicating their embryonic origin by way of a color code (in the schematic sections, medial is to the left and dorsal is to the top). In rodents, there are two major subpopulations of GABAergic projection neurons in the globus pallidus: (1) GABA+/PV+/LANT6+ neurons that show descending projections to the subthalamic nucleus and substantia nigra pars reticulata (part of these cells also have collaterals projecting to the entopeduncular nucleus), and (2)
$\mathrm{GABA}+/ \mathrm{ppENK}+$ neurons that primarily project to the striatum, although some of them appear to have descending collaterals. The $\mathrm{GABA}+/ \mathrm{PV}+/ \mathrm{LANT} 6+$ neurons primarily originate in the MGE (the pallidal progenitor zone) from cells that express $\mathrm{Nkx} 2.1$ and Lhx6, while the GABA+/ppENK+ neurons appear to originate in the LGE (the striatal progenitor zone) from cells that express Islet1. The pallidal mantle also contains neurons expressing Lhx7/8, but these represent cholinergic neurons belonging to the corticopetal system, which mainly originate in the commissural preoptic domain. For abbreviations see list. (including the caudoputamen) were characterized by the expression of the transcription factors Gsh1 (low), Gsh2 (high), Dlx1/2/5, Islet1 and Pax6, while MGE vz and/or svz and mantle (including the globus pallidus) were characterized by Gsh1 (high), Gsh2 (low) and Dlx1/2/5, but also Nkx2.1, Lhx6 and Lhx7/8 (fig. 1; see references above for more details). LGE vz/svz lacked expression of Nkx2.1 and Lhx6/7/8, while MGE vz/svz lacked expression of Pax6 and Islet1. Loss-of-function studies have revealed a pivotal role of Gsh2 and Nkx2.1 in subpallial patterning and in the specification of either LGE or MGE, respectively, and have shown that they are upstream of other transcription factors (such as Dlx1/2, Lhx6 and Lhx7/8) involved in the migration and/or differentiation of subpallial neurons [Sussel et al., 1999; Marín et al., 2000; Yun et al., 2001, 2003; Zhao et al., 2003; Cobos et al., 2007; reviewed by Medina and Abellán, 2012].

However, new developmental data have complicated this scheme due to the existence of: (1) multiple progenitor subdivisions within both LGE and MGE, each giving rise to different neuron subpopulations, a question that is still being investigated [Stenman et al., 2003; Flames et al., 2007; Bupesh et al., 2011a, b], and (2) tangential migration of neurons from MGE and other embryonic domains to the developing striatum, but also from LGE and other embryonic domains to the developing pallidum, contributing to the neuronal diversity found in the mature nuclei of the basal ganglia [Marín et al., 2000; Marín and Rubenstein, 2001; Zhao et al., 2003; Cocas et al., 2009; NóbregaPereira et al., 2010, Bupesh et al., 2011a, b; Medina and 
Abellán, 2012; Bupesh et al., 2013]. Regarding tangential migrations, the first to be described were those from the MGE and the adjacent entopeduncular $\operatorname{area}^{2}$ to the caudoputamen; they were demonstrated to produce most subtypes of striatal interneurons, including those containing parvalbumin (PV), those containing acetylcholine, most of the neuropeptide Y/somatostatin/nitric oxide synthase-expressing interneurons, and most of the calretinin-containing interneurons [Marín et al., 2000]. Recent evidence has shown that most (if not all) cholinergic interneurons of the caudoputamen really originate in the preoptic area and depend on the expression of both Lhx7/8 and Islet1 [Elshatory and Gan, 2008; GarcíaLópez et al., 2008; reviewed by Medina and Abellán, 2012]. In addition, a recent study showed that most of the dopaminergic interneurons of the striatum also migrate tangentially from the preoptic area [Bupesh et al., 2013]. In contrast to most interneurons, projection neurons of the caudoputamen (containing either substance P, SP, or enkephalin, ENK, amounting to $90-95 \%$ of all striatal neurons [Medina and Reiner, 1995]) originate in the LGE and migrate radially into the mantle [Marín and Rubenstein, 2001].

These findings, together with results on the development of the cerebral cortex, suggest that, in the telencephalon, the principal neurons of nuclei/areas arrive by radial migration from their progenitor zone (which is located topologically deeper), while tangential migration of cells beyond their original radial histogenetic domain only contributes interneurons ${ }^{3}$ [Marín and Rubenstein, 2001]. However, recent evidence has shown that this cannot be considered a general rule, since there are several examples of projection neurons that arrive to subpallial nuclei by tangential migration [Nóbrega-Pereira et al., 2010; Bupesh et al., 2011a; Medina and Abellán, 2012]. In particular, the GABAergic projection neurons of the globus pallidus include two major subpopulations ${ }^{4}$ : (1) a subpopulation of neurons that primarily originate in the

\footnotetext{
2 The entopeduncular area, initially defined as a large embryonic territory at the telencephalic stalk [Marín et al., 2000; Puelles et al., 2000], related to cerebral peduncle, has been later redefined based on gene expression patterns and separated into a part related to the MGE and another Shh-expressing part belonging to the preoptic area [Flames et al., 2007; García-López et al., 2008; Bupesh et al., 2011b].

Oligodendrocytes can also migrate tangentially [Olivier et al., 2001; Kessaris et al., 2006], but they are not considered in this review.

4 In addition to the GABAergic projection neurons, the globus pallidus contains a small subpopulation of cholinergic neurons of $\mathrm{Nkx} 2.1$ lineage that immigrate from the preoptic area (fig. 1 [Nóbrega-Pereira et al., 2010]), but these belong to the corticopetal functional system and are not treated here [reviewed by Medina and Abellán, 2012].
}

MGE (with a minor contribution of the preoptic area) and express $\mathrm{Nkx} 2.1$, with many neurons also expressing the transcription factor ER81 and the protein PV (other data show that these neurons also express the transcription factor Lhx6, which is downstream of $\mathrm{Nkx} 2.1$ ), and (2) a subpopulation of neurons that originate in the LGE and express the transcription factor Islet1 [Sussel et al., 1999; Flandin et al., 2010; Nóbrega-Pereira et al., 2010; Bupesh et al., 2011a] (fig. 1). The first subpopulation of neurons is the most abundant (about $74 \%$ of the total cell number are from the Nkx2.1 lineage, and almost $50 \%$ of the total number contain Nkx2.1, ER81 and PV [Nóbrega-Pereira et al., 2010]). This Nkx2.1 lineage cell subpopulation is not formed in mice with lack of function of Nkx2.1 [Nóbrega-Pereira et al., 2010], a transcription factor until now considered essential for the specification of MGE and the formation of the globus pallidus [Sussel et al., 1999; Marín et al., 2000]. However, it now appears that, in Nkx2.1-knockout mice, neurons of the globus pallidus derived from the LGE (about 25\% of total neurons) remain and aggregate in the correct location where this nucleus usually develops [Nóbrega-Pereira et al., 2010].

Importantly, these data help to understand the functional anatomical organization of the globus pallidus, whose neurons are heterogeneous regarding their anatomical, neurochemical and physiological features. Previous studies in adult rodents and primates reported the existence of two major GABAergic projection neurons in the globus pallidus, containing either PV+/LANT6+ (these are about $2 / 3$ of all neurons in the nucleus) or preproENK (ppENK+) [Reiner and Carraway, 1987; Reiner and Anderson, 1993; Kita, 1994; Kita and Kitai, 1994; Hoover and Marshall, 1999; Kita et al., 1999; Kita and Kita, 2001; Hoover and Marshall, 2002] (fig. 1). It is likely that most of the ppENK+ neurons represent non-PV projection neurons that contain calbindin [Cooper and Stanford, 2002], although this has not been explored by double labeling. In addition to PV+ and non-PV projection neurons (ppENK+ and/or calbindin + ), in rodents the globus pallidus also appears to contain a minor subpopulation of interneurons that express calretinin $(<1 \%$ of all neurons [Cooper and Stanford, 2002]; fig. 1). PV+ neurons typically show descending projections to the entopeduncular nucleus (medial globus pallidus), subthalamic nucleus and the substantia nigra pars reticulata [Kita and Kitai, 1994; Hoover and Marshall, 1999, 2002], although in rodents and primates some of them also appear to project to the striatum [Kita et al., 1999; Mallet et al., 2012]. In contrast, ppENK+ neurons primarily have 
ascending projections back to the striatum, although at least some of them also appear to have collaterals targeting the subthalamic nucleus and apparently the entopeduncular nucleus [Hoover and Marshall, 1999, 2002]. The PV+ cells show high-frequency discharges, while those containing ENK appear to fire low-frequency discharges punctuated by bursts [Hoover and Marshall, 1999]. Moreover, these two types of neurons differ in their response to dopamine receptor agonists or antagonists [Hoover and Marshall, 1999, 2002]. For example, dopamine $\mathrm{D}_{2}$ antagonists induce Fos protein expression exclusively in the ppENK+ neurons of the globus pallidus [Hoover and Marshall, 2002], making these cells similar to the enkephalinergic neurons of the striatum, from which the globus pallidus receives input [Hoover and Marshall, 1999]. These two major subtypes of neurons have also been found in the globus pallidus of parkinsonian rats [Mallet et al., 2012].

It now appears that these two major types of projection neurons of the globus pallidus have distinct embryonic origins (fig. 1). As noted above, the $\mathrm{PV}+$ projection neurons of the globus pallidus appear to originate in the Nkx2.1-expressing embryonic domain, primarily in the MGE [Nóbrega-Pereira et al., 2010]. In contrast, the ppENK+ pallidostriatal neurons likely represent the LGE-derived, non-PV neurons of the globus pallidus found to express Islet1 [Nóbrega-Pereira et al., 2010; Bupesh et al., 2011a]. Interestingly, this second type of neuron of the globus pallidus with origin in the LGE shows dendritic architecture (with high density of spines), chemical features (expression of ENK) and pharmacological responses (to dopamine receptor antagonist) similar to one of the major projection neurons of the caudoputamen (the enkephalinergic projection neurons) and appears to show reciprocal connections with this nucleus [Hoover and Marshall, 2002; Mallet et al., 2012], which also originates in the LGE. This is not surprising since the embryonic origin of any single neuron has a strong influence on its future chemical features, connections and physiological characteristics. In the mouse centromedial extended amygdala, which is highly heterogeneous regarding neuron constitution and embryonic origin, there is also a trend for neurons having the same origin to share similar chemical features and connections, and to be involved in similar functions [García-López et al., 2008; Bupesh et al., 2011a, b; Medina et al., 2011; Abellán et al., 2013]. Thus, developmental studies have provided key information for a better understanding of the functional anatomical organization of the globus pallidus in mammals. In addition,

Evolution and Development of the Basal Ganglia this information establishes the basis for a better comparison with the globus pallidus of other vertebrates, as done below.

\section{The Globus Pallidus in Nonmammals: What Defines the Nucleus and What Cells Originated First?}

From the data above, it appears that the mammalian globus pallidus contains two major subpopulations of GABAergic projection neurons: those from the Nkx2.1 lineage that primarily originate in the MGE, most of which express PV and show the typical descending projections mainly to the subthalamic nucleus and substantia nigra (many of these PV+ cells also show collaterals to the entopeduncular nucleus), and those that originate in the LGE, from the Islet1 lineage, and likely represent the ppENK-containing pallidostriatal projection neurons (note that here we are not considering neurons of the corticopetal system that overlap the pallidum; fig. 1). This information is extremely important if we want to understand the evolutionary origin of this nucleus. Until now, researchers in the field of basal ganglia have considered that the globus pallidus is defined as a subpallial nucleus whose neurons originate in the MGE from the Nkx2.1 cell lineage [Sussel et al., 1999; Marín et al., 2000; Puelles et al., 2000], express GABA and PV, receive input from the striatum and project to subthalamic/nigral targets [Medina and Reiner, 1995; Reiner et al., 1998]. However, this definition is only partially true, since some of the projection neurons of the nucleus clearly originate in the LGE and do not belong to the MGE/Nkx2.1 lineage. Moreover, such cells do not express PV, and their most characteristic projections are those to the striatum (although some also appear to project to the subthalamus and perhaps other targets). However, many features of the non-PV neurons of the globus pallidus in other mammals remain unknown. Therefore, the definition of the nucleus is not simple and is far from clear. One way to approach the question is to ask which neuron subtypes are present in the globus pallidus of nonmammals, and what defined the evolutionary origin of this nucleus (table 1).

\section{Sauropsids (Birds and Reptiles)}

Based on position, neurochemistry and connections, many studies have identified a dorsal striatopallidal neural system in different birds and reptiles, which is comparable to that of mammals [reviewed by Medina and Reiner, 1995; Reiner et al., 1998]. The globus pallidus thus identified contains GABAergic neurons, also coexpress- 
Table 1. Characteristics of the pallidum in different species of vertebrates

\begin{tabular}{|c|c|c|c|c|}
\hline & $\begin{array}{l}\text { Pallidal embryonic } \\
\text { domain (Nkx2.1) }\end{array}$ & $\begin{array}{l}\text { Distinction of } \\
\mathrm{DP}(\mathrm{GP}) \text { and VP }\end{array}$ & $\begin{array}{l}\text { Cell types according to } \\
\text { embryonic origin }\end{array}$ & $\begin{array}{l}\text { Cell types } \\
\text { based on neurochemistry }\end{array}$ \\
\hline Mouse & yes & yes & $\begin{array}{l}\text { Nkx2.1, Lhx6 (MGE/Pa) } \\
\text { Islet1 (LGE/St) } \\
\text { Lhx7/8 (PO) }\end{array}$ & $\begin{array}{l}\text { GABA/PV/LANT6 } \\
\text { GABA/ENK/CB } \\
\text { CR } \\
\text { CHAT }\end{array}$ \\
\hline Chicken & yes & yes & $\begin{array}{l}\text { Nkx2.1, Lhx6 (Pa) } \\
\text { Islet1 (St) } \\
\text { Lhx7/8 (PO) }\end{array}$ & $\begin{array}{l}\text { GABA/PV/LANT6 } \\
\text { GABA/ENK } \\
\text { GABA/SP } \\
\text { CHAT }\end{array}$ \\
\hline Turtle, lizard & yes & yes & $\begin{array}{l}\text { Nkx2.1(Pa) } \\
\text { Pax6 } \\
? ?\end{array}$ & $\begin{array}{l}\text { GABA/PV/LANT6 } \\
\text { CHAT } \\
\text { ?? }\end{array}$ \\
\hline Frog & yes & yes & $\begin{array}{l}\text { Nkx2.1 (Pa) } \\
\text { Islet1 } \\
\text { Lhx7/8 (PO) }\end{array}$ & $\begin{array}{l}\text { GABA/LANT6 } \\
\text { ENK } \\
\text { CB } \\
\text { CHAT }\end{array}$ \\
\hline Lungfish & yes & yes? & $\begin{array}{l}\text { Nkx2.1(Pa) } \\
\text { Islet1 (St) }\end{array}$ & $\begin{array}{l}\text { GABA/LANT6 } \\
\text { ENK } \\
\text { SP }\end{array}$ \\
\hline Teleost & yes & no & $\begin{array}{l}\text { Nkx2.1, Lhx6 }(\mathrm{Pa}) \\
\operatorname{Lhx7}(\mathrm{PO})\end{array}$ & $\begin{array}{l}\text { GABA/LANT6 } \\
\text { ENK } \\
\text { SP } \\
\text { CHAT }\end{array}$ \\
\hline Dogfish & yes & no & Nkx2.1 (Pa) & GABA/LANT6 \\
\hline Lamprey & no & - & - & - \\
\hline
\end{tabular}

ing PV and LANT6, that receive input from the striatum and project to the subthalamic nucleus and substantia nigra pars reticulata (table 1). Recent evidence on the development of the telencephalon in chicken and turtles has shown that the nucleus identified as globus pallidus in these animals is rich in Nkx2.1-expressing cells that appear to derive from a MGE-like embryonic domain (the pallidal embryonic subdivision; fig. 2) [Fernandez et al., 1998; Puelles et al., 2000; Cobos et al., 2001; Abellán and Medina, 2009; Moreno et al., 2010; Kuenzel et al., 2011]. Thus, the globus pallidus in sauropsids appears to contain at least the pallido/Nkx2.1 lineage cell type, expressing GABA, PV and LANT6, and with descending projections to the subthalamic nucleus and substantia nigra, comparable to a similar type found in the globus pallidus of rodents and primates (table 1). In sauropsids, this cell type may also be responsible for the descending pallidal pro- jections to a pretectotectal nucleus, which are prominent in these animals [Reiner et al., 1980; Medina and Smeets, 1991; Reiner et al., 1998].

In addition to this major cell type, the globus pallidus in chicken also contains subpopulations of neurons expressing ppENK or SP+ mRNA [Abellán and Medina, 2009] (table 1). The embryonic origin of these cells is unclear, but it is likely that they derive from the striatal progenitor (LGE-like) zone, as the projection neurons of the striatum (containing either ENK or SP) do [Abellán and Medina, 2009]. In agreement, in chicken the developing globus pallidus includes a subpopulation of neurons expressing the transcription factor Islet1 [unpubl. obs.], which is present in cells derived from the ventral striatal progenitor domain (table 1). It is also likely that ppENK+ and $\mathrm{SP}+$ neurons of the chicken globus pallidus, as those in the dorsal striatum [Reiner et al., 1998], represent 


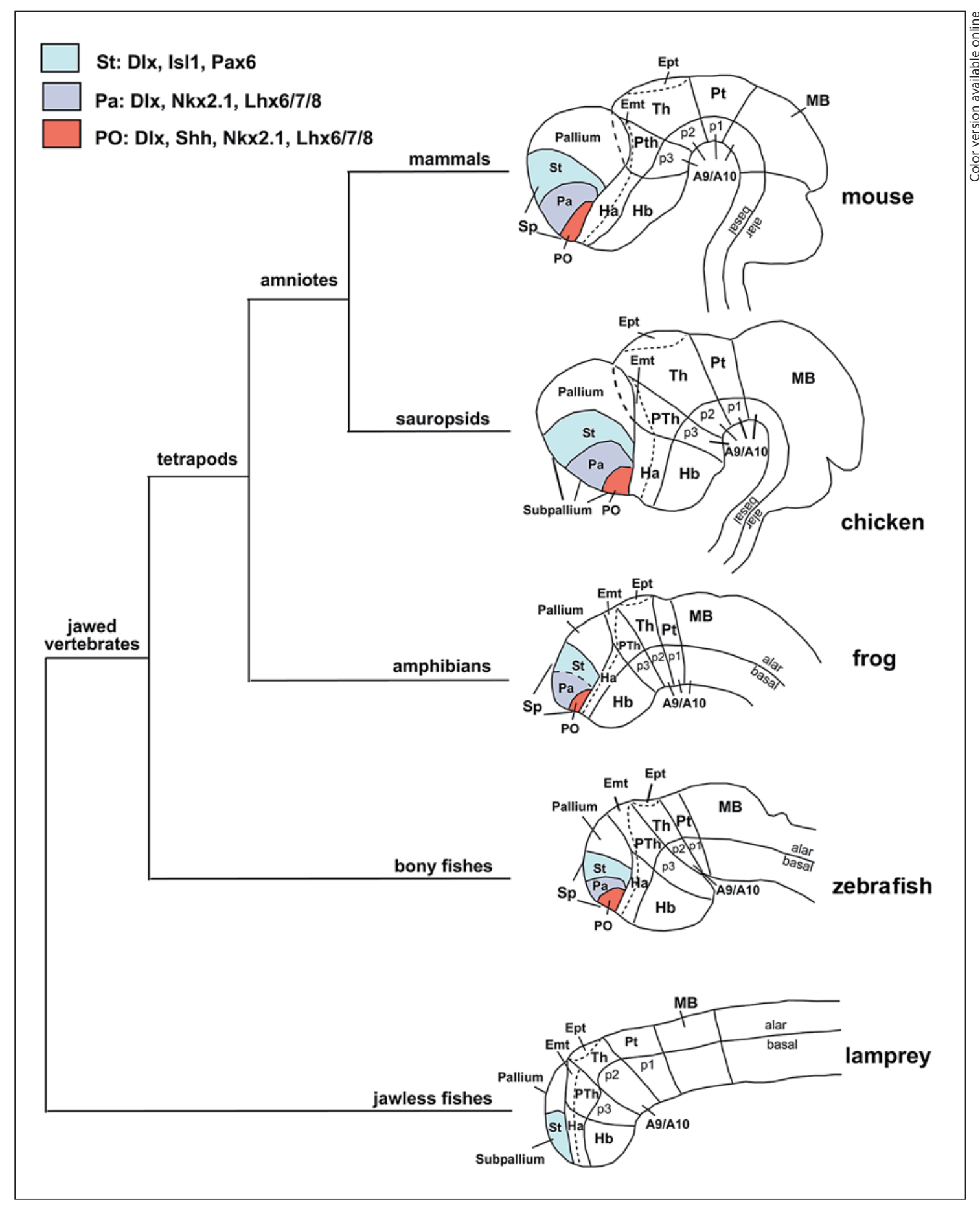

Fig. 2. Phylogenetic diagram that shows the subpallial subdivisions found in embryos of different vertebrates. As shown in the diagram, in jawed vertebrates there are three major subpallial subdivisions: the striatal domain (in mammals called LGE), the pallidal domain (in mammals called MGE) and the preoptic domain. All three express Dlx-related transcription factors at the progenitor zone (vz/svz), but the combinatorial expression of Nkx2.1, Shh, together with Islet1, Pax6, Lhx6 and Lhx7/8 (the latter only available in some species) at restricted parts of the $\mathrm{vz}$ and/or svz allows the distinction of the three subpallial subdivisions. In zebrafish, only one copy of $\mathrm{Nkx} 2.1$ ( Nk2.1b) is expressed in the subpallium. On the other hand, lampreys lack expression of Nkx2.1 and Hedgehog in the telencephalon, and thus appear to lack the pallidopreoptic embryonic subdivisions and the cell groups derived from them. However, the situation in lampreys may represent a simplification with respect to the ancestral condition, and data in hagfishes are needed in order to know what was the situation in the first vertebrates [Sugahara et al., 2013]. For abbreviations see list. 
mostly segregated subpopulations. If the latter is true, it would mean that the globus pallidus in chicken contains more neuron subpopulations than that in rodents: pallidal/Nkx2.1 lineage neurons expressing PV and LANT6; striatal/Islet1 lineage neurons expressing ppENK, and striatal/Islet1 lineage neurons expressing SP. The chicken ppENK+ neurons may be comparable to the LGE-derived ppENK+ pallidostriatal projection neurons of rodents, but the connections of these cells in chicken are unknown. On the other hand, the globus pallidus of turtles appears to contain a few cells expressing Pax6 [Moreno et al., 2010] (table 1), but their origin and phenotype are unclear. Other questions that arise are: what are the projections of the SP+ cells present in the chicken globus pallidus? Are these similar to those of the SP+ neurons of the striatum? Are the ppENK+ neurons and/or the SP+ neurons also present in the globus pallidus of other sauropsids? What are their functions? Were all of these cells present in the globus pallidus of the common amniote ancestor? Is there any mammal with a subpopulation of $\mathrm{SP}+$ neurons in the globus pallidus?

\section{Amphibians}

As in amniotes, a dorsal striatopallidal system, with a dorsal striatum and a dorsal pallidum/globus pallidus, has been identified in amphibians based on position, neurochemical features and connections [reviewed by Marín et al., 1998], which has been supported by developmental studies [Moreno et al., 2009]. In frogs and salamanders, the developing globus pallidus is rich in neurons expressing $\mathrm{Nkx} 2.1$ that derive from the pallidal progenitor domain (table 1; fig. 2) [González et al., 2002; Moreno and González, 2007; van den Akker et al., 2008; Moreno et al., 2009], similarly to the main subpopulation of globus pallidus neurons of amniotes. These neurons appear comparable to the $\mathrm{Nkx} 2.1$ lineage neurons of the amniote globus pallidus, most of which are PV+. However, it is unknown whether the Nkx2.1 lineage cells of amphibians contain PV or LANT6. In contrast, the globus pallidus in frogs and salamanders contains abundant cells expressing calbindin (table 1) [Morona and González, 2008], although the embryonic origin of these cells is unknown. On the other hand, it seems that in the frog Xenopus laevis, the globus pallidus also contains minor subpopulations of cells expressing the transcription factor Islet 1 [Moreno et al., 2008] or the neuropeptide proENK [Merchenthaler et al., 1989]. Although more studies are needed, these cells of the frog may derive from the striatal progenitor zone and be comparable to similar cells found in the globus pallidus of the mouse and chicken (table 1). More studies will also be necessary to investigate the presence of SP+ cells in the globus pallidus of amphibians. Taken together, these data show that the globus pallidus of all tetrapods includes at least two major subtypes of neurons, those of Nkx2.1 lineage primarily derived from the pallidal progenitor domain and those of Islet 1 lineage that apparently derive from the striatal progenitor domain (table 1).

\section{Fishes}

A striatum and a pallidum were identified in lungfishes, ray-finned fishes and cartilaginous fishes based on neurochemical features [Reiner and Northcutt, 1987; Northcutt et al., 1988; Reiner and Northcutt, 1992; Northcutt, 2009], but their delineation has improved thanks to data on the expression of transcription factors during development [Wullimann and Mueller, 2004; Mueller et al., 2008; González and Northcutt, 2009; Mueller and Wullimann, 2009; Quintana-Urzainqui et al., 2012; reviewed by González et al., 2014]. In particular, the pallidal division, which contains neurons of Nkx2.1 and/or Lhx6 lineage (table 1; fig. 2) [Mueller et al., 2008; González and Northcutt, 2009; Mueller and Wullimann, 2009; Quintana-Urzainqui et al., 2012], appears to receive ENK+ and $\mathrm{SP}+$ input from the striatum and also contains LANT6+ cells [Reiner and Northcutt, 1987, 1992; reviewed by González et al., 2014]. Importantly, data on Nkx2.1 expression in lungfishes and cartilaginous fishes have revealed that the pallidal subdivision is smaller (more medially restricted) than previously thought [González and Northcutt, 2009; Quintana-Urzainqui et al., 2012]. On the other hand, in the teleost zebrafish (used as a neurogenetic model for ray-finned fishes), there are two copies of $\mathrm{Nkx} 2.1$, and only one of them (Nk2.1b) is expressed in the subpallium [Rohr et al., 2001]. Detailed analysis of this zebrafish region using expression of Lhx6 (also a pallidal marker in amniotes, being downstream to $\mathrm{Nkx} 2.1$ ) has revealed that it corresponds to a ventral subdivision of the dorsal part of the ventral or subpallial telencephalic sector (Vd or Sd) [Mueller et al., 2008; Mueller and Wullimann, 2009], as previously proposed by Reiner and Northcutt [1992] based on neurochemistry and position.

Interestingly, it appears that at least in lungfishes the pallidal division (defined by Nkx2.1 expression) also includes a subpopulation of Islet1 lineage neurons that may derivefrom the striatal progenitor zone (table 1) [González and Northcutt, 2009]. The Nkx2.1/Lhx6 pallidal division of lungfishes and ray-finned fishes [Mueller et al., 2008; González and Northcutt, 2009] also contains ENK+ and SP+ neurons (table 1) [Reiner and Northcutt, 1987, 1992; Northcutt, 2009], but the embryonic origin of these cells 
is unknown. Thus, it is possible that two major cell types, the pallido/Nkx2.1 lineage neurons and the striato/Islet1 lineage neurons, were present in the pallidum of the common ancestor of lungfishes and tetrapods, or perhaps in earlier ancestors (based on the presence of ENK + and SP+ neurons in the pallidum of ray-finned and cartilaginous fishes), but we need additional studies, including analysis of Islet1, in more species to confirm this. Moreover, although it is suggested that the pallidum of jawed fishes receives striatal input, this is mostly based on immunohistochemical observations. Nevertheless, there is an experimental study on the connections of the subpallium in a teleost fish (the rainbow trout) that shows the existence of intrinsic subpallial connections, some of which may represent reciprocal striatopallidal projections [Folgueira et al., 2004].

Data in lampreys have shown lack of a Nkx2.1 expression in the telencephalon, indicating the absence of an MGE-like progenitor zone in these jawless fishes (fig. 2; table 1) [Murakami et al., 2001, 2005; Osorio et al., 2005] and perhaps in the first vertebrates (however, the situation in lampreys may represent a simplification with respect to the ancestral condition, and data in other extant jawless fishes, e.g. hagfishes ${ }^{5}$, are necessary to determine the situation at the origin of vertebrates) [Sugahara et al., 2013]. The lack of Nkx2.1 expression in the subpallium of lampreys is correlated with the lack of Hedgehog, which is suggested to be upstream of Nkx2.1 [Murakami et al., 2005; Osorio et al., 2005] (see discussion below; fig. 2). The subpallium, identified by its expression of Dlx family genes [Murakami et al., 2001], appears to include only the LGE-like progenitor zone that produces the striatum (fig. 2). This is in agreement with the description of a striatal-like sector, but not a pallidum, in the subpallium of lampreys based on neurochemistry [Pombal et al., 1987; Nieuwenhuys and Nicholson, 1998; see also discussion in van den Akker et al., 2008; Medina, 2009]. However, a recent study has found evidence for the presence of pallidal cells in lampreys based on neurochemistry, connections and physiology [Stephenson-Jones et al., 2011]. Yet,

\footnotetext{
5 There are no data on Nk2.1/Nkx2.1 in hagfishes (lineage of jawless fishes that diverged close to the origin of vertebrates). On the other hand, amphioxus (a cephalochordate) lacks a telencephalon [Holland, 2009] and in these animals Nk2.1 is expressed at basal diencephalic levels, resembling the expression of Nk2.1/Nkx2.1 at this location in vertebrates [Venkatesh et al., 1999].

6 Note that expression of developmental regulatory genes, combined with other landmarks, is very useful for understanding the topological framework of the neural tube, the major divisions/subdivisions and the primary topological position of cell groups within the tube [Puelles and Medina, 2002; Medina, 2007].
}

Evolution and Development of the Basal Ganglia the topological position of the proposed pallidum (highly important for any consideration of homology) [Nieuwenhuys, 1998; Striedter, 2005; Nieuwenhuys, 2009] ${ }^{6}$ does not appear compatible with its homology to the pallidum of jawed vertebrates, unless their cells left their primary location (the domain where they originated) and migrated tangentially to a position adjacent to the thalamic eminence. Moreover, in the apparent absence of Nkx2.1 lineage neurons in the subpallium, the only type of neurons that may be present in such putative "pallidum' of lampreys are those of striatal lineage, which may be comparable to the LGE/Islet1 lineage cells found in the pallidum of lungfish, frog, chicken and mouse. In any case, more studies need to be conducted in different species to be sure of the evolutionary continuity and homology of such cells.

\section{Final Remarks: What Defines the Globus Pallidus, When Did This Nucleus First Appear and What Triggered Its Evolution?}

As noted above, the globus pallidus (dorsal pallidum) of tetrapods appears to contain two major types of GABAergic projection neurons, those derived from the MGE/pallidal embryonic subdivision and expressing Nkx2.1 and those derived from the LGE/striatal subdivision and expressing Islet1. The connections and neuropeptide content of these two cell types are different. The pallidum in lungfishes also appears to include both types of neurons. However, in ray-finned and cartilaginous fishes, there is only evidence for the presence of Nkx2.1 lineage cells, but more studies need to be conducted to investigate the presence Islet1 lineage cells (although this seems possible due to the presence of $\mathrm{ENK}+$ and $\mathrm{SP}+$ cells). Moreover, in the absence of enough connectivity/ functional data, it is unclear whether the pallidal domain of lungfishes, ray-finned fishes and cartilaginous fishes is subdivided into dorsal and ventral parts comparable to those in tetrapods, although it seems plausible in lungfishes due to the similarity of their subpallium to that of amphibians [González and Northcutt, 2009]. In this sense, a true globus pallidus (dorsal pallidum) may first be seen at the time of origin of tetrapods or perhaps a little earlier (with the common ancestor of lungfishes and tetrapods) and be characterized by the presence of two major neuron types. Nevertheless, data on the neuropeptide content and connections of each one of these cell types in different species are still missing. 


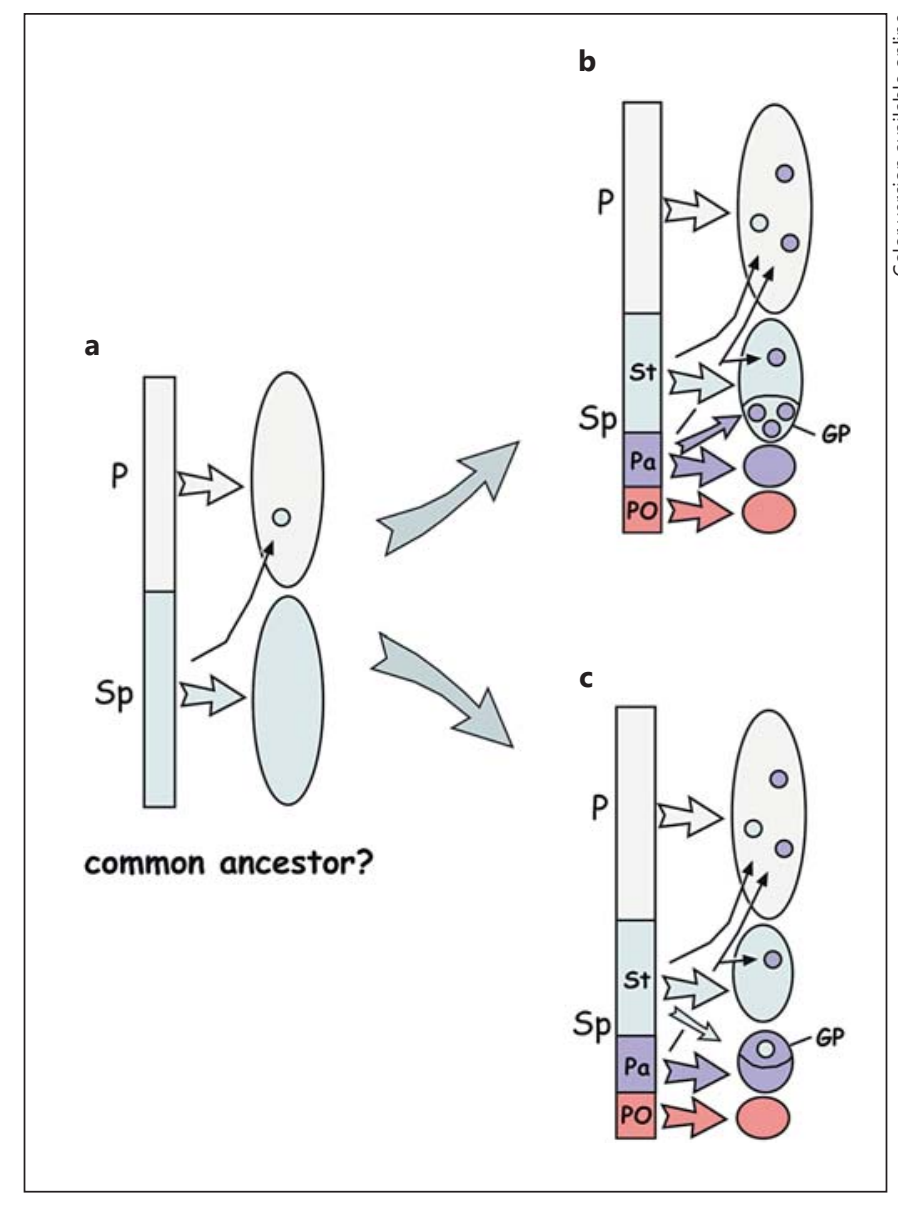

Fig. 3. Diagram representing two possible modes of development and evolution of the globus pallidus $(\mathbf{b}, \mathbf{c})$, diverging from the situation found in the common ancestor (a; without embryonic subdivisions in the subpallium). The globus pallidus in tetrapods and lungfishes appears to include two major cell subpopulations, those from the pallidal domain (expressing Nkx2.1 during development) and those from the striatal domain (expressing Islet1 during development). The mixing of the two subpopulations may occur by tangential migration of striatal-derived cells into the pallidal mantle to join there other cells and together form the GP (situation represented in c; apparently found in frogs and mice). Alternatively, this may occur by massive tangential migration of many pallidal-derived cells into the striatal mantle, where they find striatal cells (situation represented in $\mathbf{b}$; apparently found in chicken). For abbreviations see list.

On the other hand, the pallidal embryonic division (comparable to the MGE) appears to be present in all jawed vertebrates, but not in the jawless lamprey (based on the absence of expression of Nkx2.1 in the subpallium of these fishes). Data in other extant jawless fishes (such as hagfishes) are needed to know whether the MGE was or was not present at the origin of vertebrates. Neverthe- less, if the pallidum (at least its dorsal part or globus pallidus) of jawed vertebrates also contains neurons from the LGE/Islet lineage, it is still possible that at least such type of neurons (a subpopulation of striatal-lineage neurons, interconnected with other striatal neurons, and perhaps with descending collaterals to the subthalamus) was present in the first vertebrates as part of the basal ganglia circuit. If this was the case, can we call this cell group, having only striatal-derived neurons without any contribution of cells from the pallidal/MGE embryonic domain, as a 'pallidum' without entering into at least semantic contradictions? It is clear that the cells of such a putative cell group (with only striatal-lineage neurons) would only be homologous to the LGE/striatal-lineage neurons of the pallidum of tetrapods.

When the pallidal embryonic subdivision appears, the globus pallidus may either: (1) form de novo with cells from the new domain, with later addition of striatal cells that migrate tangentially from their original domain, or (2) may evolve from a previous subdivision of the striatum that acquires new properties by massive incorporation of cells derived from the novel embryonic domain. One way to approach this question is to analyze what happens during the development of the globus pallidus in different species: (a) do the pallido-Nkx2.1 cells migrate tangentially to meet a previously formed group of striatal cells, as represented in figure $3 \mathrm{~b}$, or (b) do the striato/Islet 1 cells migrate tangentially to meet a previously formed group of pallido/Nkx2.1 cells, as represented in figure $3 \mathrm{c}$ ? Based on observations of published material, it appears that the second possibility may occur in frogs (fig. 3i of Moreno et al. [2008]) and mice [García-López et al., 2008; Nóbrega-Pereira et al., 2010; Bupesh et al., 2011a], but the first possibility appears to occur in chicken [Abellán and Medina, 2009]. However, the situation is unclear in lungfishes (see fig. 4c, d of González and Northcutt [2009]) and we lack data from reptiles, and for now it is not possible to know what was the ancestral condition.

In any case, a major step in the evolution of the basal ganglia and the telencephalon likely was the appearance of a novel expression domain of $\mathrm{Nkx} 2.1$ in the subpallium [Murakami et al., 2005; Osorio et al., 2005; Medina, 2009; Moreno et al., 2009; Kuenzel et al., 2011]. What triggered the novel expression of Nkx2.1 in the subpallium? This has been correlated to the novel expression of Hedgehog/ Sonic hedgehog (Shh), which was not seen in lampreys but is present in a similar location to Nkx2.1 in jawed fishes and tetrapods [Puelles et al., 2000; Rohr et al., 2001; Murakami et al., 2005; Osorio et al., 2005; Flames et al., 2007; García-López et al., 2008; van den Akker et al., 2008; 
Abellán and Medina, 2009; Domínguez et al., 2010; Quintana-Urzainqui et al., 2012]. It was suggested that Hedgehog/Shh maybe upstream to and drive the expression of Nkx2.1 in the basal telencephalon [Murakami et al., 2005; Osorio et al., 2005]. This was shown for Hedgehog in zebrafish (inducing Nk2.1b [Rohr et al., 2001]), resembling a similar role of Shh in relation to Nkx2.1 in mouse [reviewed by Medina and Abellán, 2012]. In addition, another possibility (compatible with the previous one), which was suggested by an in silico comparative study, is the occurrence of changes in the regulatory region of Nkx2.1 during evolution [van der Akker et al., 2008]. According to this study, the regulatory region of $\mathrm{Nkx} 2.1$ appears to contain a highly conserved enhancer, which is present in mouse, chicken, the frog Xenopus tropicalis, the fugu (puffer fish, a basal teleost) and also in the regulatory region of zebra fish Nk2.1b [van der Akker et al., 2008]. In contrast, such a domain shows a large deletion in the zebrafish Nk2.1a, which is not expressed in the telencephalon [van der Akker et al., 2008]. Nk2.1a of zebrafish shows an expression pattern similar to that of $\mathrm{Nkx} 2.1$ of lampreys, in which such an enhancer could not be found. Therefore, although more studies are needed, these data suggest the existence of at least two mechanisms involved in triggering a novel expression domain of Nkx2.1 in the telencephalon. Given the relevance of the cell groups produced by the Nkx2.1 embryonic domain (not only related to the basal ganglia but also as a source of cortical interneurons and the corticopetal telencephalic cell groups [Marín and Rubenstein, 2001; Medina and Abellán, 2012]), this became a major event in the evolution of the forebrain.

\section{Acknowledgements}

This study was supported by a grant from the Spanish Ministry of Economy and Competitivity, and Fondo Europeo de Desarrollo Regional (FEDER): grant No. BFU2012-33029.

\section{Disclosure Statement}

The authors have nothing to disclose.

\section{References}

Abellán A, Desfilis E, Medina L (2013): The olfactory amygdala in amniotes: an evo-devo approach. Anat Rec (Hoboken) 296:1317-1332.

Abellán A, Medina L (2009): Subdivisions and derivatives of the chicken subpallium based on expression of LIM and other regulatory genes and markers of neuron subpopulations during development. J Comp Neurol 515:465501.

Albin RL, Young AB, Penney JB (1989): The functional anatomy of basal ganglia disorders. Trends Neurosci 12:366-375.

- Bupesh M, Abellán A, Medina L (2011a): Genetic and experimental evidence supports the continuum of the central extended amygdala and a mutiple embryonic origin of its principal neurons. J Comp Neurol 519:3507-3531.

- Bupesh M, Legaz I, Abellán A, Medina L (2011b): Multiple telencephalic and extratelencephalic embryonic domains contribute neurons to the medial extended amygdala. J Comp Neurol 519:1505-1525.

Bupesh M, Vicario A, Abellán A, Desfilis E, Medina L (2013): Dynamic expression of tyrosine hydroxylase mRNA and protein in neurons of the striatum and amygdala of mice, and experimental evidence of their multiple embryonic origin. Brain Struct Funct, Epub ahead of print.

\section{Carney RS, Mangin JM, Hayes L, Mansfield K, Sousa VH, Fishell G, Machold RP, Ahn S, Gal- lo V, Corbin JG (2010): Sonic hedgehog ex- pressing and responding cells generate neuro- nal diversity in the medial amygdala. Neural Dev 5:14. \\ Carroll SB, Grenier JK, Weatherbee SD (2001): From DNA to Diversity. Molecular Genetics and the Evolution of Animal Design. Cam- bridge, Blackwell.}

Cobos I, Borello U, Rubenstein JLR (2007): Dlx transcription factors promote migration through repression of axon and dendrite growth. Neuron 54:873-888.

Cobos I, Shimamura K, Rubenstein JL, Martínez S, Puelles L (2001): Fate map of the avian anterior forebrain at the four-somite stage, based on the analysis of quail-chick chimeras. Dev Biol 239:46-67.

Cocas LA, Miyoshi G, Carney RS, Sousa VH, Hirata T, Jones KR, Fishell G, Huntsman MM, Corbin JG (2009): Emx1-lineage progenitors differentially contribute to neural diversity in the striatum and amygdala. J Neurosci 29: 15933-15946.

Cooper AJ, Stanford IM (2002): Calbindin D-28k positive projection neurones and calretinin positive interneurones of the rat globus pallidus. Brain Res 929:243-251.
Domínguez L, González A, Moreno N (2010): Sonic hedgehog expression during Xenopus laevis forebrain development. Brain Res 1347: 19-32.

-Elshatory Y, Gan L (2008): The LIM-homeobox gene Islet-1 is required for the development of restricted forebrain cholinergic neurons. J Neurosci 28:3291-3297.

-Fentress JC, Stanfield BB, Cowan WM (1981) Observation on the development of the striatum in mice and rats. Anat Embryol (Berl) 163:275-298.

Fernandez AS, Pieau C, Repérant J, Boncinelli E, Wassef M (1998): Expression of the Emx-1 and Dlx-1 homeobox genes define three molecularly distinct domains in the telencephalon of mouse, chick, turtle and frog embryos: implications for the evolution of telencephalic subdivisions in amniotes. Development 125:2099-2111.

Flames N, Pla R, Gelman DM, Rubenstein JL, Puelles L, Marín O (2007): Delineation of multiple subpallial progenitor domains by the combinatorial expression of transcriptional codes. J Neurosci 27:9682-9695.

Flandin P, Kimura S, Rubenstein JL (2010): The progenitor zone of the ventral medial ganglionic eminence requires $\mathrm{Nkx} 2-1$ to generate most of the globus pallidus but few neocortical interneurons. J Neurosci 30:2812-2823. 
Folgueira M, Anadón R, Yáñez J (2004): An experimental study of the connections of the telencephalon in the rainbow trout (Oncorhynchus mykiss). I: Olfactory bulb and ventral area. J Comp Neurol 480:180-203.

- García-López M, Abellán A, Legaz I, Rubenstein JL, Puelles L, Medina L (2008): Histogenetic compartments of the mouse centromedial and extended amygdala based on gene expression patterns during development. J Comp Neurol 506:46-74.

Gerfen CR (2004): Basal ganglia; in Paxinos G (ed): The Rat Nervous System, ed 3. Amsterdam, Elsevier-Academic Press, pp 455-508.

González A, López JM, Marín O (2002a): Expression pattern of the homeobox protein NKX21 in the developing Xenopus forebrain. Brain Res Gene Expr Patterns 1:181-185.

-Gonzalez A, Lopez JM, Sanchez-Camacho C, Marın O (2002b): Regional expression of the homeobox gene NKX2-1 defines pallidal and interneuronal populations in the basal ganglia of amphibians. Neuroscience 114:567-575.

-González A, Morona R, Moreno N, Bandín S, López JM (2014): Identification of striatal and pallidal regions in the subpallium of anamniotes. Brain Behav Evol 83:93-103.

González A, Northcutt RG (2009): An immunohistochemical approach to lungfish telencephalic organization. Brain Behav Evol 74:4355.

Graybiel AM, Saka E (2004): The basal ganglia and the control of action; in Gazzaniga MS (ed): The Cognitive Neurosciences III, ed 3. Cambridge, MIT Press, pp 495-510.

- Grigoriu M, Tucker AS, Sharpe PT, Pachnis V (1998): Expression and regulation of Lhx6 and Lhx7, a novel subfamily of LIM homeodomain encoding genes, suggests a role in mammalian head development. Development 125:2063-2074.

-Hirata T, Li P, Lanuza GM, Cocas LA, Huntsman MM, Corbin JG (2009): Identification of distinct telencephalic progenitor pools for neuronal diversity in the amygdala. Nat Neurosci 12:141-149.

Holland LZ (2009): Chordate roots of the vertebrate nervous system: expanding the molecular toolkit. Nat Rev Neurosci 10:736-746.

Holmgren N (1925): Points of view concerning forebrain morphology in higher vertebrates. Acta Zool 6:413-477.

-Hoover BR, Marshall JF (1999): Population characteristics of preproenkephalin mRNA-containing neurons in the globus pallidus of the rat. Neurosci Lett 265:199-202.

Hoover BR, Marshall JF (2002): Further characterization of preproenkephalin mRNA-containing cells in the rodent globus pallidus. Neuroscience 111:111-125.

-Kessaris N, Fogarty M, Iannarelli P, Grist M, Wegner M, Richardson WD (2006): Competing waves of oligodendrocytes in the forebrain and postnatal elimination of an embryonic lineage. Nat Neurosci 9:173-179.
Kita H (1994): Parvalbumin-immunopositive neurons in rat globus pallidus: a light and electron microscopic study. Brain Res 657: 31-41.

Kita H, Kita T (2001): Number, origins, and chemical types of rat pallidostriatal projection neurons. J Comp Neurol 437:438-448.

Kita H, Kitai ST (1994): The morphology of globus pallidus projection neurons in the rat: an intracellular staining study. Brain Res 636: 308-319.

Kita H, Tokuno H, Nambu A (1999): Monkey globus pallidus external segment neurons projecting to the neostriatum. Neuroreport 10: 1467-1472.

Kuenzel WJ, Medina L, Csillag A, Perkel DJ, Reiner A (2011): The avian subpallium: new insights into structural and functional subdivisions occupying the lateral subpallial wall and their embryological origins. Brain Res 1424: 67-101.

Lanciego JL, Luquin N, Obeso JA (2012): Functional neuroanatomy of the basal ganglia. Cold Spring Harb Perspect Med 2:a009621.

Mallet N, Micklem BR, Henny P, Brown MT, Williams C, Bolam JP, Nakamura KC, Magill PJ (2012): Dichotomous organization of the external globus pallidus. Neuron 74:1075-1086.

Marchand R, Lajoie L (1986): Histogenesis of the striopallidal system in the rat. Neurogenesis of its neurons. Neuroscience 17:573-590.

Marín O, Anderson SA, Rubenstein JLR (2000): Origin and molecular specification of striatal interneurons. J Neurosci 20:6063-6076.

-Marín O, Rubenstein JLR (2001): A long, remarkable journey: tangential migration in the telencephalon. Nat Rev Neurosci 2:780-790.

-Marín O, Smeets WJ, González A (1998): Evolution of the basal ganglia in tetrapods: a new perspective based on recent studies in amphibians. Trends Neurosci 21:487-494.

Medina L (2007): Field homologies; in Kaas JH, Striedter GF, Rubenstein JLR (eds): Evolution of Nervous Systems: A Comprenhensive Reference. Amsterdam, Elsevier-Academic Press, vol 1: Theories, Development, Invertebrates, pp 73-87.

Medina L (2009): Basal ganglia: evolution; in Squirre L (ed): Encyclopedia of Neuroscience. Oxford, Elsevier-Academic Press, vol 2, pp 67-85.

Medina L, Abellán A (2012): Subpallial structures; in Watson C, Paxinos G, Puelles L (eds): The Mouse Nervous System. Amsterdam, Elsevier-Academic Press, pp 173-220.

Medina L, Bupesh M, Abellán A (2011): Contribution of genoarchitecture to understanding forebrain evolution and development, with particular emphasis on the amygdala. Brain Behav Evol 78:216-236.

Medina L, Reiner A (1995): Neurotransmitter organization and connectivity of the basal ganglia in vertebrates: implications for the evolution of basal ganglia. Brain Behav Evol 46:235-258.

Medina L, Smeets WJAJ (1991): Comparative aspects of the basal ganglia-tectal pathways in reptiles. J Comp Neurol 308:614-629.
Merchenthaler I, Lázár G, Maderdrut JL (1989): Distribution of proenkephalin-derived peptides in the brain of Rana esculenta. J Comp Neurol 281:23-39.

-Moreno N, Domínguez L, Rétaux S, González A (2008): Islet1 as a marker of subdivisions and cell types in the developing forebrain of Xenopus. Neuroscience 154:1423-1439.

Moreno N, González A (2007): Regionalization of the telencephalon in urodele amphibians and its bearing on the identification of the amygdaloid complex. Front Neuroanat 1:1-12.

Moreno N, González A, Rétaux S (2009): Development and evolution of the subpallium. Semin Cell Dev Biol 20:735-743.

-Moreno N, Morona R, López JM, González A (2010): Subdivisions of the turtle Pseudemys scripta subpallium based on the expression of regulatory genes and neuronal markers. J Comp Neurol 518:4877-4902.

Morona R, González A (2008): Calbindin-D28k and calretinin expression in the forebrain of anuran and urodele amphibians: further support for newly identified subdivisions. J Comp Neurol 511:187-220.

Mueller T, Wullimann MF (2009): An evolutionary interpretation of teleostean forebrain anatomy. Brain Behav Evol 74:30-42.

Mueller T, Wullimann MF, Guo S (2008): Early teleostean basal ganglia development visualized by zebrafish Dlx2a, Lhx6, Lhx7, Tbr2 (eomesa), and GAD67 gene expression. J Comp Neurol 507:1245-1257.

-Murakami Y, Ogasawara M, Sugahara F, Hirano S, Satoh N, Kuratani S (2001): Identification and expression of the lamprey Pax6 gene: evolutionary origin of the segmented brain of vertebrates. Development 128:3521-3531.

-Murakami Y, Uchida K, Rijli FM, Kuratani S (2005): Evolution of the brain developmental plan: insights from agnathans. Dev Biol 280: 249-259.

Nieuwenhuys R (1998): Comparative neuroanatomy: place, principles and programme; in Nieuwenhuys R, ten Donkelaar HJ, Nicholson C (eds): The Central Nervous System of Vertebrates. Berlin, Springer, vol. 1, pp 273326.

Nieuwenhuys R (2009): The forebrain of actinopterygians revisited. Brain Behav Evol 73: 229-252.

Nieuwenhuys R, Nicholson C (1998): Lampreys, Petromyontoidea; in Nieuwenhuys $\mathrm{R}$, ten Donkelaar HJ, Nicholson C (eds): The Central Nervous System of Vertebrates. Berlin, Springer, vol. 1, pp 397-495.

-Nóbrega-Pereira S, Gelman D, Bartolini G, Pla R, Pierani A, Marín O (2010): Origin and molecular specification of globus pallidus neurons. J Neurosci 30:2824-2834.

Northcutt RG (2009): Telencephalic organization in the spotted African lungfish, Protopterus dolloi: a new cytological model. Brain Behav Evol 73:59-80. 
Northcutt RG, Reiner A, Karten HJ (1988): Immunohistochemical study of the telencephalon of the spiny dogfish, Squalus acanthias. J Comp Neurol 277:250-267.

-Olivier C, Cobos I, Perez Villegas EM, Spassky N, Zalc B, Martinez S, Thomas JL (2001): Monofocal origin of telencephalic oligodendrocytes in the anterior entopeduncular area of the chick embryo. Development 128:1757-1769.

- Osorio J, Mazan S, Rétaux S (2005): Organisation of the lamprey (Lampetra fluviatilis) embryonic brain: insights from LIM-homeodomain, Pax and hedgehog genes. Dev Biol 288: $100-112$.

Pombal MA, El Manira A, Grillner S (1997): Organization of the lamprey striatum - transmitters and projections. Brain Res 766:249254.

- Puelles L, Kuwana E, Puelles E, Bulfone A, Shimamura K, Keleher J, Smiga S, Rubenstein JLR (2000): Pallial and subpallial derivatives in the embryonic chick and mouse telencephalon, traced by the expression of the genes Dlx-2, Emx-1, Nkx-2.1, Pax-6, and Tbr-1. J Comp Neurol 424:409-438.

Puelles L, Medina L (2002): Field homology as a way to reconcile genetic and developmental variability with adult homology. Brain Res Bull 57:243-255.

Quintana-Urzainqui I, Sueiro C, Carrera I, Ferreiro-Galve S, Santos-Durán G, Pose-Méndez S, Mazan S, Candal E, Rodríguez-Moldes I (2012): Contributions of developmental studies in the dogfish Scyliorhinus canicula to the brain anatomy of elasmobranchs: insights on the basal ganglia. Brain Behav Evol 80:127141.

Reiner A, Anderson KD (1993): Co-occurrence of gamma-aminobutyric acid, parvalbumin and the neurotensin-related neuropeptide LANT6 in pallidal, nigral and striatal neurons in pigeons and monkeys. Brain Res 624:317-325.

- Reiner A, Brauth SE, Kitt CA, Karten HJ (1980): Basal ganglionic pathways to the tectum: studies in reptiles. J Comp Neurol 193:565589.
Reiner A, Carraway RE (1987): Immunohistochemical and biochemical studies on Lys8Asn9-neurotensin8-13 (LANT6)-related peptides in the basal ganglia of pigeons, turtles, and hamsters. J Comp Neurol 257:453476.

Reiner A, Medina L, Veenman CL (1998): Structural and functional evolution of the basal ganglia in vertebrates. Brain Res Brain Res Rev 28:235-285.

Reiner A, Northcutt RG (1987): An immunohistochemical study of the telencephalon of the African lungfish, Protopterus annectens. J Comp Neurol 256:463-481.

Reiner A, Northcutt RG (1992): An immunohistochemical study of the telencephalon of the Senegal bichir (Polypterus senegalus). J Comp Neurol 319:359-386.

Rodríguez-Moldes I (2009): A developmental approach to forebrain organization in elasmobranchs: new perspectives on the regionalization of the telencephalon. Brain Behav Evol 74:20-29.

Rohr KB, Barth KA, Varga ZM, Wilson SW (2001): The nodal pathway acts upstream of hedgehog signaling to specify ventral telencephalic identity. Neuron 29:341-351.

-Stenman J, Toresson H, Campbell K (2003): Identification of two distinct progenitor populations in the lateral ganglionic eminence: implications for striatal and olfactory bulb neurogenesis. J Neurosci 23:167-174.

Stephenson-Jones M, Ericsson J, Robertson B, Grillner S (2012): Evolution of the basal ganglia: dual-output pathways conserved throughout vertebrate phylogeny. J Comp Neurol 520:2957-2973.

-Stephenson-Jones M, Samuelsson E, Ericsson J, Robertson B, Grillner S (2011): Evolutionary conservation of the basal ganglia as a common vertebrate mechanism for action selection. Curr Biol 21:1081-1091.

Striedter GF (2005): Principles of Brain Evolution. Sunderland, Sinauer.
Sugahara F, Murakami Y, Adachi N, Kuratani S (2013): Evolution of the regionalization and patterning of the vertebrate telencephalon: what can we learn from cyclostomes? Curr Opin Genet Dev 23:475-483.

- Sussel L, Marin O, Kimura S, Rubenstein JLR (1999): Loss of Nkx2.1 homeobox gene function results in a ventral to dorsal molecular respecification within the basal telencephalon: evidence for a transformation of the pallidum into the striatum. Development 126: 3359-3370.

van den Akker WM, Brox A, Puelles L, Durston AJ, Medina L (2008): Comparative functional analysis provides evidence for a crucial role for the homeobox gene Nkx2.1/Titf- 1 in forebrain evolution. J Comp Neurol 506:211-223.

-Venkatesh TV, Holland ND, Holland LZ, Su MT, Bodmer R (1999): Sequence and developmental expression of amphioxus AmphiNk2-1: insights into the evolutionary origin of the vertebrate thyroid gland and forebrain. Dev Genes Evol 209:254-259.

Wullimann MF, Mueller T (2004): Teleostean and mammalian forebrains contrasted: evidence from genes to behavior. J Comp Neurol 475:143-162.

Xu Q, Tam M, Anderson SA (2008): Fate mapping Nkx2.1-lineage cells in the mouse telencephalon. J Comp Neurol 506:16-29.

-Yun K, Garel S, Fischman S, Rubenstein JLR (2003): Patterning of the lateral ganglionic eminence by the Gsh1 and Gsh2 homeobox genes regulates striatal and olfactory bulb histogenesis and the growth of axons through the basal ganglia. J Comp Neurol 461:151-165.

-Yun K, Potter S, Rubenstein JLR (2001): Gsh2 and Pax6 play complementary roles in dorsoventral patterning of the mammalian telencephalon. Development 128:193-205.

Zhao Y, Marin O, Hermesz E, Powell A, Flames N, Palkovits M, Rubenstein JLR, Westphal H (2003): The LIM-homeobox gene Lhx8 is required for the development of many cholinergic neurons in the mouse forebrain. Proc Natl Acad Sci USA 100:9005-9010. 